\title{
Alteration of the 4-sphingenine scaffolds of ceramides in keratinocyte-specific Arnt-deficient mice affects skin barrier function
}

\author{
Satoshi Takagi, ${ }^{1,2}$ Hiromasa Tojo, ${ }^{3}$ Shuhei Tomita, ${ }^{4}$ Shigetoshi Sano, ${ }^{5}$ Satoshi Itami, ${ }^{5}$ \\ Mariko Hara, ${ }^{6}$ Shintaro Inoue, ${ }^{6}$ Kyoji Horie,,${ }^{1,7}$ Gen Kondoh, ${ }^{1}$ Ko Hosokawa, ${ }^{2}$ \\ Frank J. Gonzalez, ${ }^{8}$ and Junji Takeda ${ }^{1,7}$ \\ ${ }^{1}$ Department of Social and Environmental Medicine, \\ ${ }^{2}$ Department of Plastic Surgery, and \\ ${ }^{3}$ Department of Biochemistry and Molecular Biology, Osaka University Graduate School of Medicine, Osaka, Japan \\ ${ }^{4}$ Department of Immune System Development, RIKEN Research Center for Allergy and Immunology, Tokushima, Japan \\ ${ }^{5}$ Department of Dermatology, Osaka University Graduate School of Medicine, Osaka, Japan \\ ${ }^{6}$ Basic Research Laboratory, Kanebo Ltd., Kanagawa, Japan \\ ${ }^{7}$ Collaborative Research Center for Advanced Science and Technology, Osaka, Japan \\ ${ }^{8}$ Laboratory of Metabolism, National Cancer Institute, Bethesda, Maryland, USA
}

Aryl hydrocarbon receptor nuclear translocator (ARNT), a transcription factor of the Per/AHR/ ARNT/Sim family, regulates gene expression in response to environmental stimuli including xenobiotics and hypoxia. To examine its role in the epidermis, the Cre-loxP system was used to disrupt the Arnt gene in a keratinocyte-specific manner. Gene-targeted, newborn mice with almost normal appearance died neonatally of severe dehydration caused by water loss. Histology showed small changes in the architecture of cornified layers, with apparently preserved intercorneocyte lamellar structures responsible for the skin barrier function. In contrast, HPLC/ion-trap mass spectrometry revealed significant alterations in the compositions of ceramides, the major components of the lamellae. The murine epidermal ceramides normally contain 4-sphingenine and 4-hydroxysphinganine. In Arnt-null epidermis, 4-sphingenine was largely replaced by sphinganine and the amounts of ceramides with 4-hydroxysphinganine were greatly decreased, suggesting deficiency of dihydroceramide desaturases that catalyze the formation of both 4-sphingenyl and 4-hydroxysphinganyl moieties. A desaturase isoenzyme, DES-1, prefers desaturation, but DES-2 catalyzes both reactions to a similar extent. Transcript levels of Des-2, but not Des-1, were considerably decreased in cultured keratinocytes from Arntnull epidermis. These results indicate that proper ceramide compositions through 4-desaturation regulated by ARNT are crucial for maintaining the epidermal barrier function.

J. Clin. Invest. 112:1372-1382 (2003). doi:10.1172/JCI200318513.

\section{Introduction}

Aryl hydrocarbon receptor nuclear translocator (ARNT) is a member of the basic helix-loop-helix-Per/ AHR/ARNT/Sim (bHLH-PAS) family of proteins and forms transcriptionally active heterodimers with a variety of other bHLH-PAS proteins, including aryl hydrocarbon receptor (AHR) and hypoxia-inducible factor $1 \alpha(\mathrm{HIF} 1 \alpha)$. Binding of ligands such as 2,3,7,8-tetra-

Received for publication April 1, 2003, and accepted in revised form August 26, 2003.

Address correspondence to: Junji Takeda, Department of Social and Environmental Medicine H3, Osaka University Graduate School of Medicine, Osaka 565-0871, Japan.

Phone: 81-6-6879-3262; Fax: 81-6-6879-3266;

E-mail: takeda@mr-envi.med.osaka-u.ac.jp.

Conflict of interest: The authors have declared that no conflict of interest exists.

Nonstandard abbreviations used: aryl hydrocarbon receptor nuclear translocator (ARNT); basic helix-loop-helix (bHLH); aryl hydrocarbon receptor (AHR); Per/AHR/ARNT/Sim (PAS); hypoxia-inducible factor $1 \alpha$ (HIF1 $\alpha$ ); stratum corneum (SC); high-performance TLC (HPTLC); tandem mass spectrometry (MS/MS); embryonic day (E); electrospray ionization (ESI). chlorodibenzo-p-dioxin to the AHR induces formation of a transcriptionally active AHR/ARNT heterodimer that upregulates xenobiotic metabolizing enzymes (1). In a similar manner, a reduction in the concentration of cellular oxygen stabilizes HIF $1 \alpha$, and then the HIF $1 \alpha /$ ARNT complexes activate genes involved in adaptation to hypoxia (2). ARNT can also function as a homodimer to activate transcription of genes driven by the $\mathrm{E}$ box core sequences, although the physiological role of this activity is unknown (3). The bHLH-PAS proteins can be classified as sensors and partners (1). The sensors, such as AHR and HIF $1 \alpha$, act by detecting environmental contaminants through AHR ligand binding and atmospheric or cellular oxygen, respectively. The partner, ARNT, is required for the dimerization with the sensors to interact with the target sequence. Thus, it was proposed that PAS family proteins function as sensors for environmental adaptation (1). In situ hybridization analysis shows that Arnt mRNA emerges as early as embryonic day 9.5 at a number of sites, including many ectodermal tissues, and is expressed in many tissues, including the skin, at postnatal day $1.5(4,5)$. 
The skin provides a protective barrier between the body and the environment, blocking the penetration of microorganisms and harmful chemicals and preventing the loss of body fluid. The protective barrier is mainly confined to the epidermis, since isolated epidermis is impermeable and the residual dermis is completely permeable. Acute disruption of the protective barrier in the epidermis by acetone treatment or tape stripping resulted in a rapid increase in the synthesis of lipids, leading to barrier repair. The epidermis, therefore, is responsible for keeping unpredicted environmental stimuli from disrupting homeostasis.

To explore a possible role of PAS family proteins in the environmental adaptation in the epidermis, we applied a conditional gene-targeting strategy using the Cre-loxP system, resulting in the generation of keratinocyte-specific Arnt-deficient mice. Arnt-null mice obtained by conventional gene targeting are embryonic-lethal, largely because of defective vascularization of the placenta and/or yolk sac $(6,7)$.

In this study, we were able to demonstrate that keratinocyte-specific ablation of the Arnt gene resulted in severe impairment of the barrier functions that is mainly mediated by the outermost layer of the skin, the stratum corneum (SC). SC is formed from granular-layer keratinocytes during terminal differentiation and consists of an array of dead and keratin-filled cells (cornified cells) embedded in a matrix of lamellar lipids, which are glued together with extremely tough materials known as the cornified envelope. The cornified envelope consists of two parts, a protein envelope made of specific cornified-cell structural proteins cross-linked by the action of transglutaminase 1 (8), and a lipid envelope esterified to the exterior of the protein envelope. Defects in the genes encoding either structural proteins (9) or transglutaminase 1 (10) have been known to affect the formation of the protein envelope, leading to impaired barrier function (10). The lamellar lipids also determine the quality of the barrier, since substances penetrate the SC by passive diffusion through the intercellular spaces. The lipids found in SC have an unusual composition, consisting of ceramides, cholesterol, and FFAs in approximately equal quantities (11). Moreover, SC ceramides represent a unique and heterogeneous species of at least eight ceramides $(12,13)$. In the Arnt-null mice, precise analysis with mass spectrometry revealed that 4-sphingenine was largely replaced by sphinganine and that the amounts of ceramides with 4-hydroxysphinganine were greatly decreased, although changes in the architecture of the SC, observed by electron microscopy (EM), were minimal. These results indicate that the bHLH-PAS family transcription factor ARNT unpredictably regulates ceramide biosynthesis through 4-desaturation and that maintenance of ceramide compositions is important for barrier function.

\section{Methods}

Generation of keratinocyte-specific Arnt gene-targeted mice and genotyping. Generation of heterozygous Arnt-floxed $\left(\right.$ Arnt $\left.f^{\text {lox }(n e o) /+}\right)$ mice containing the Neo cassette was pre- viously described (14). The mice were then crossed with EIIa-Cre mice (15) to generate either an Arnt-null allele $\left(A r n t^{+/-}\right)$or Arnt-floxed allele $\left(A r n t^{\text {flox } /+}\right)$ without the $\mathrm{Neo}$ cassette. The Arnt ${ }^{+/-}$mice were mated with $\mathrm{K5}$-Cre transgenic mice (16), and their offspring carrying both the K5-Cre transgene and the Arnt-null allele $\left(\mathrm{K}-\mathrm{Cre}^{+} \mathrm{Arnt} \mathrm{t}^{+-}\right)$were mated with $\mathrm{Arnt} \mathrm{t}^{\text {flox/flox }}$ mice to produce $\mathrm{K5}$-Cre ${ }^{+} \mathrm{Arnt} \mathrm{flox}^{\mathrm{fl}}$ mice.

The genotyping was examined by PCR using the genomic DNA obtained from the clipped tail. Detection of the K5-Cre transgene was described previously (16). Primers used for the Arnt gene were AF-5 (5'-CACCTGAGCTAAATTACCAGGCC), AR-4 (5'-GCATGCTGGCACATGCCTGTCT), and AR-2 (5'-GTGAGGCAGATTTCTTCCATGCTC). Using a mixture of these primers, PCR was performed with 35 cycles of a reaction consisting of 1 minute of denaturation at $93^{\circ} \mathrm{C}, 1$ minute of annealing at $57^{\circ} \mathrm{C}$, and 2 minutes of elongation at $72^{\circ} \mathrm{C}$. PCR products were $190 \mathrm{bp}, 307 \mathrm{bp}$, and $328 \mathrm{bp}$, specific for wild, floxed, and null alleles, respectively.

Preparation of epidermis. To separate epidermal keratinocytes from dermis, full-thickness skin taken from newborn mice was treated with $10 \mathrm{mM}$ EDTA in PBS at $37^{\circ} \mathrm{C}$ for 1 hour.

$R T-P C R$. Total RNA was isolated from the keratinocytes and the liver of newborn mice using TRIzol reagent (Invitrogen Corp., Carlsbad, California, USA) according to the manufacturer's instructions. cDNA was synthesized with an oligo-dT primer. PCR was performed to amplify a portion of Arnt cDNA using the primers Arnt-U (5'-TAACCATCTTACGCATGGCC) and Arnt-L (5'-TAGTACCACACCTCATGCGG). GAPDH cDNA was amplified as control.

Skin-permeability assay. Unfixed, untreated pups were incubated with methanol at increasing concentrations of $25 \%, 50 \%, 75 \%$, and $100 \%$ for 1 minute each to modify the skin so as to permit barrier-dependent penetration by histological dyes. They were then rinsed in PBS, followed by incubation in $0.1 \%$ toluidine blue (17).

Measurement of trans-epidermal water loss. Trans-epidermal water loss from the skin of neonatal mice was examined under normal conditions using a TM210 Tewameter (COURAGE + KHAZAKA electronic Co., Cologne, Germany), as described previously (10).

Histological analysis. For conventional light-microscopic observations, tissues processed into approximately 5$\mu \mathrm{m}$ paraffin sections were subjected to staining with H\&E. For immunohistochemical staining, anti-keratin 1 , anti-keratin 5 , anti-keratin 6 , anti-keratin 10 , antifilaggrin, and anti-involucrin antibodies (all from Berkeley Antibody Co., Richmond, California, USA) were used. Frozen sections were stained with the first antibodies and then incubated with FITC-conjugated rabbit anti-mouse antibodies (DAKO Cytomation A/S, Glostrup, Denmark). Electron-microscopic analysis by the method of Hou et al. was performed (18). Briefly, skin samples excised from the newborn mice were minced into 2 -mm-square pieces and fixed at $4{ }^{\circ} \mathrm{C}$ in $1.6 \%$ paraformaldehyde $/ 2 \%$ glutaraldehyde in $0.1 \mathrm{M}$ 
sodium cacodylate buffer ( $\mathrm{pH}$ 7.4) (40\%-strength Karnovsky's fixative). Samples were placed in $1 \%$ osmium tetroxide in $0.1 \mathrm{M}$ cacodylate buffer for 1 hour and then in $0.2 \%$ ruthenium tetroxide with $0.25 \%$ potassium ferrocyanide for 4 hours. After dehydration through a graded-concentration ethanol series, the tissue was equilibrated in propylene oxide and embedded in Spurr's resin. Ultrathin sections were double-stained with uranyl acetate and lead, and examined with a JEM100S (JEOL Ltd., Akishima, Japan) electron microscope.

Lipid extraction from SC. The epidermal layer of newborn mice was peeled off from full-thickness skin dipped into PBS at $60^{\circ} \mathrm{C}$ for 10 seconds. SC was then isolated from the underlying nucleated layers of the epidermis by incubation with $0.5 \%$ trypsin in PBS $\left(4^{\circ} \mathrm{C}\right.$ overnight). Total lipids were isolated from epidermis or SC samples by the method of Bligh and Dyer (19), as previously described (20) or with hexane/2-propanol (3:2 vol/vol) followed by washing with $6.7 \% \mathrm{Na}_{2} \mathrm{SO}_{4}(21)$. For mass spectrometry, the latter method was usually used.

$T L C$. The major epidermal and SC lipid species were separated by high-performance TLC (HPTLC; Merck KGaA, Darmstadt, Germany). Cholesterol, FFA, and triglyceride were developed first with benzene/hexane $(50: 50 \mathrm{vol} / \mathrm{vol})$ to $4 \mathrm{~cm}$, and then with benzene/ ethanol/acetic acid (70:30:1 vol/vol/vol) to $8 \mathrm{~cm}$. Individual ceramide species were separated by HPTLC using the method of Uchida et al. (22).

Mass spectrometry of ceramides. Epidermal ceramide molecular species were identified by electrospray ionization (ESI)-ion-trap mass spectrometry connected online with normal-phase HPLC (23). The HPLC system consisted of two Gilson model 302 liquid-delivery modules, a Gilson model 811 dynamic mixer (Gilson SAS, Villiers Le Bel, France), and a trap column $(1 \times 20 \mathrm{~mm})$, and two Valco switching valves (Valco Instruments Co., Houston, Texas, USA) were used to remove components eluting earlier and later than the ceramides. Ceramide species were separated on a column $(1 \times 150 \mathrm{~mm})$ packed with LiChrospher Si 100 silicas (Merck KGaA) pre-equilibrated with solvent A, hexane/2-propanol (100:0.5 vol/vol) containing $0.1 \%$ formic acid, which was developed with a linear gradient of solvent B, hexane/2-propanol/ ethanol (40:50:10 vol $/ \mathrm{vol} / \mathrm{vol})$ containing $5 \mathrm{mM}$ ammonium formate, from $0 \%$ to $50 \%$ in 40 minutes at a flow rate of $50 \mu \mathrm{l} / \mathrm{min}$. To facilitate ionization of ceramides in the less polar solvents A and B by ESI, solvent C, 2-propa$\mathrm{nol} / \mathrm{ethanol}(1: 1 \mathrm{vol} / \mathrm{vol})$ containing $10 \mathrm{mM}$ ammonium formate, was delivered with another Gilson pump (model 302 liquid delivery module; Gilson SAS) at a flow rate of $25 \mu \mathrm{l} / \mathrm{min}$, and mixed via a tee with the effluent from the column. The mixture was monitored with a Thermo Finnigan LCQ mass spectrometer (Thermo Electron Corp., Yokohama, Japan) equipped with an ESI ion source in alternate positive- and negative-ion full scan, and datadependent positive-ion tandem mass spectrometry (MS/MS) modes in a single run. The LiChrospher Si 100 silicas (Merck KGaA) were slurry-packed into a column (1 $\times 150 \mathrm{~mm}, 1 \times 20 \mathrm{~mm}$, or $2.1 \times 30 \mathrm{~mm}$ ) in our laboratory.
Real-time PCR quantitation of desaturase mRNAs. mRNAs for Des-1, Des-2, and $\beta$-actin were quantified by PCR with fluorescently labeled oligonucleotide hybridization probes on a LightCycler instrument (Roche Diagnostics Gmbh, Mannheim, Germany). Primer pairs were 5'TCTTGAAGGGACACGAAAC and 5'-CCGTCACAAAGTCATAGAGC for desaturase $1,5^{\prime}$-ATATGTTCCTGAAGGGCCAC and 5'-TGCGCTTAACCCTGGAGTAG for desaturase 2, and 5'-CTGGCACCACACCTTCTACA and 5'-CCTCGTAGATGGGCACAGTG for $\beta$-actin. Probes were 5 -CATGGTGAGGAAGATCGCAAGTGAG-fluorescein and 5'-LC Red 640-ACTACGATGACCTCCCGCACTACAACT-phosphate for desaturase 1, 5'-AACACCACGACTTCCCCAGTATCCC-fluorescein and $5^{\prime}$-LC Red 640-GGTTACTACCTGCCACTGGTGCGGA-phosphate for desaturase 2, and 5'-CCAACCGTGAAAAGATGACCCAGATC-fluorescein and 5'-LC Red 640-TGTTTGAGACCTTCAACACCCCAGC-phosphate for $\beta$-actin. Real-time PCR was performed using the LightCycler FastStart DNA Master Hybridization Probes kit (Roche Diagnostics). The reaction mix contained $0.5 \mu \mathrm{M}$ of each primer, $0.2 \mu \mathrm{M}$ of fluorescein probe, and $0.4 \mu \mathrm{M}$ of LC Red 640 probe. $0.31-1.3 \mathrm{ng}$ of cDNA was used from each type of keratinocyte, and $0.08 \mathrm{ng}, 0.16 \mathrm{ng}, 0.31 \mathrm{ng}$, $0.63 \mathrm{ng}$, and $1.3 \mathrm{ng}$ of cDNA aliquots from WT keratinocyte were used as standards. Amplification conditions were $95^{\circ} \mathrm{C}$ for 10 minutes for 1 cycle, followed by 45 cycles of $95^{\circ} \mathrm{C}$ denaturation for 10 seconds, $55^{\circ} \mathrm{C}$ annealing for 10 seconds, and $72^{\circ} \mathrm{C}$ polymerization for $10 \mathrm{sec}-$ onds. The quantity of each transcript was obtained from the standard curve, and the amount of desaturase 1 and desaturase 2 transcripts was divided by the amount of $\beta$-actin transcript for normalization.

Assay for dibydroceramide desaturase activity. Dihydroceramide desaturase activity was assayed by mass spectrometry. Epidermis homogenates were left to stand for $5 \mathrm{~min}$ utes to remove tissue debris, and then the supernatant was centrifuged at $100,000 \mathrm{~g}$ for 1 hour. The pellets were used as an enzyme source. The reaction mixtures contained rac- $N$-lignoceroyl-dihydrosphingosine (Sigma-Aldrich, St. Louis, Missouri, USA), NADH, NP-40, cacodylate, and the enzyme sample in a final volume of $0.2 \mathrm{ml}$. The mixtures were incubated for $1-3$ hours at $37^{\circ} \mathrm{C}$. The reactions were stopped by addition of two volumes of chloroform/ methanol (1:2 vol/vol), after which $N$-palmitoyl-dihydrosphingosine was added as the internal standard, and the lipids were extracted by the method of Bligh and Dyer (19). The extracts were washed once with chloroform/ methanol $/ 1 \% \mathrm{KCl}(3: 48: 47 \mathrm{vol} / \mathrm{vol} / \mathrm{vol})$ in water to remove water-soluble contaminants. An aliquot of extracts was injected onto a Lichrospher Si 100 column $(2.1 \times 30 \mathrm{~mm})$ pre-equilibrated with solvent $\mathrm{A}$, and the column was developed with a linear gradient of solvent B from $0 \%$ to $50 \%$ in 20 minutes at a flow rate of $50 \mu \mathrm{l} / \mathrm{min}$. The effluents were monitored with an LCQ mass spectrometer in the positive-ion mode. Ionization of ceramides was facilitated by the same method as described above. A product, $N$-lignoceroyl-sphingosine, was identified as a peak at $m / z=650$ and quantified with the internal standard $(m / z=540)$ but was hardly detected in epidermal lipid fractions. 


\section{Results}

Establishment of keratinocyte-specific Arnt-deficient mice. To investigate the biological function of ARNT in the epidermis, we inactivated the Arnt gene specifically in mouse keratinocytes using the Cre-loxP system. When mice containing an Arnt allele with exon 6 flanked by loxP sites (14) were mated with transgenic mice carrying the Cre gene under control of the keratin 5 (K5) promoter (16), the Cre-mediated gene disruption by $\mathrm{K} 5$-Cre was efficient and specific in keratinocytes, as previously reported for mice bearing Pig-a and Stat3floxed alleles $(16,24)$ (Figure 1a).

As previously described, deletion of exon 6 mediated by Cre recombinase results in the production of an aberrant Arnt mRNA that is unstable (14) and does not produce ARNT protein (S. Tomita et al., unpublished results). Loss of Arnt mRNA expression in keratinocytes from $\mathrm{K}^{2}-\mathrm{Cre}^{+} \mathrm{Arnt} \mathrm{flox}^{\mathrm{fl}-}$ (Arnt-null) mice was also ascertained by RT-PCR analysis (Figure 1b). When $\mathrm{K}^{-} \mathrm{Cre}^{+} \mathrm{Arnt}^{+/-}$and Arnt $t^{f l o x} / f l o x$ mice were interbred, all genotypes appeared in the offspring according to the mendelian distribution (Table 1), demonstrating that the keratinocyte-specific Arnt-deficient mice did not die in utero.

Arnt-null mice show severe impairment of the epidermal barrier. At birth, Arnt-null mice appeared normal and were macroscopically indistinguishable from other littermates (Figure 2a). However, they gradually became dispirited and emaciated and died within 24 hours after birth without exception. Just after birth, all of the offspring were separated from their mothers, kept at $25^{\circ} \mathrm{C}$, and weighed hourly with an electronic scale. Arnt-null mice showed rapid and steady loss of body weight, whereas the other mice maintained their weight (Figure 2b). This correlation between disruption of Arnt and weight loss was consistent.

When the epidermal barrier was examined by skin-permeability assay using $0.1 \%$ toluidine blue, impairment of the epidermal barrier in Arnt-null mice was apparent all over the body surface, particularly in the ventral neck and perineal regions (Figure 2c). This pattern was similar when Arnt-null embryos were analyzed at 17 days postcoitus (data not shown), suggesting that the unique pattern of staining observed in Arnt-null neonates is not due to postnatal environmental influence. Trans-epidermal water loss also increased in Amt-null mice (Table 2), especially in the ventral neck region, where staining with $0.1 \%$ toluidine blue was most evident. We surmised that the accelerated water loss through the epidermis results in the rapid body-weight loss followed by death within 24 hours in Arnt-null mice. When salve was applied to Arntnull mice to prevent dehydration, their weight loss was retarded and they survived longer than 24 hours (data not shown), confirming that the dehydration was the major cause of weight loss and neonatal lethality.

Histological analysis of the epidermis of Arnt-null mice. Although the skin of Arnt-null mice was macroscopically indistinguishable from that of normal mice, hyperdehydration prompted us to subject the skin of Arnt-null mice to histological examination (Figure 3a). The SC from Arnt-null mice was tightly packed. Keratohyalin granules in the granular layer appeared to be sparse in Arnt-null mice, being more evident in the ventral neck region.

A panel of antibodies against proteins expressed at defined stages of epidermal differentiation were used to examine whether Arnt deficiency affects keratinocyte maturation. Expression of keratin 5, a basal cell-specific marker, and expression of keratin 10, a marker for terminal differentiation of epidermis, were similar in WT and Arnt-null epidermis (data not shown). In addition, involucrin and filaggrin, which are early- and late-differentiation markers of keratinocytes, respectively, were observed in the upper stratum spinosum and SC in both groups of mice (data not shown). The expression of keratin 6 was strongly induced in basal cells of Arnt-null mice, especially in the ventral neck region (Figure 3b). Keratin 6 is generally expressed in a restricted subset of cells within hair follicles. In Arnt-null mice, we often detected morphologically distinct epidermal cells with condensed nuclei and eosinophilic cytoplasms (Figure 3a). These cells were identified as apoptotic keratinocytes, which have been well characterized previously as a result of UV irradiation (25).
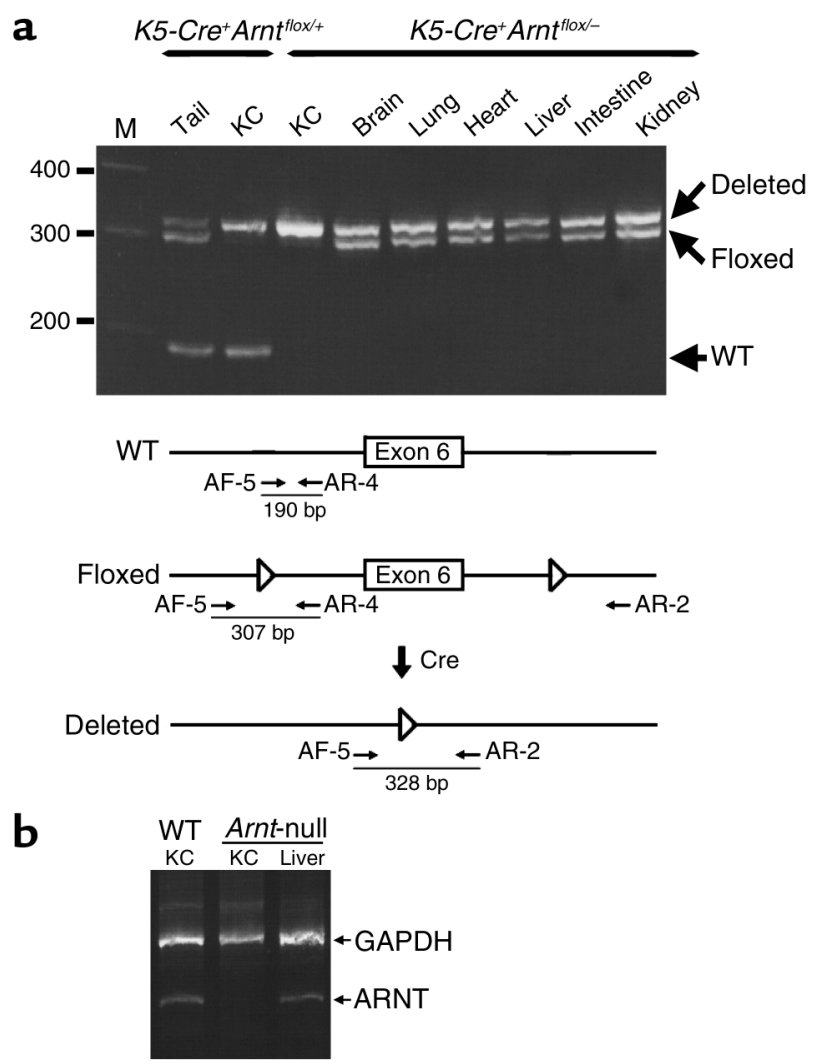

\section{Figure 1}

Generation of keratinocyte-specific Arnt-deficient mice. (a) Keratinocyte-specific disruption of the Arnt gene with the Cre-loxP system. PCR products were separated on 3\% MetaPhor Agarose gel (Cambrex, Bio Science Inc., Rockland, Maine, USA). A 100-bp ladder marker was used as a size marker. (b) Arnt mRNA in the keratinocytes was examined by RT-PCR. As a control, the GAPDH gene was amplified in all samples. KC, keratinocytes. M, 100-bp ladder marker. 
Table 1

Genotypic analysis of offspring mated with $\mathrm{K} 5-\mathrm{Cre}^{+} \mathrm{Arnt}^{+/-}$and Arnt flox flox mice

\begin{tabular}{|c|c|c|c|}
\hline K5-Cre ${ }^{+}$Arnt flox/+ & K5-Cre ${ }^{+}$Arnt $t^{f l o x /-}$ & Arnt flox/+ & Arnt $t^{f l o x /-}$ \\
\hline 47 & 43 & 44 & 35 \\
\hline
\end{tabular}

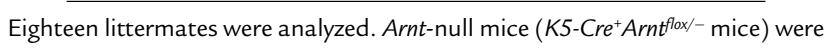
born at the mendelian ratio.

There were significantly more apoptotic cells in the epidermis of Arnt-null mice $(22.5 \pm 6.7$ cells $/ \mathrm{cm})$ than in those of WT mice $(6.3 \pm 2.1$ cells $/ \mathrm{cm})$. This was confirmed by immunostaining with an antibody against single-stranded DNA (data not shown).

The SC, composed of the individual cornified cells and intercellular lipids, has been shown to play a crucial role in the formation of epidermal barrier. To examine the structure of the SC in detail, EM was used (Figure 4, a-f). It confirmed that the SC from Arnt-null mice was tightly packed (Figure 4b), as shown in Figure 3a. In the granular-layer keratinocytes, lamellar bodies were seen in the cytoplasm and excreted normally into the SC (Figure 4, $\mathrm{c}$ and $\mathrm{d}$ ). The architecture characteristic of SC lamellae, including a broad-narrow-broad lucent band sequence, was generally preserved in Arnt-null SC, but closer analysis of scanned images of negative micrographs revealed that the spacing between the two broad lucent bands was slightly narrower in Arnt-null mice (Figure 4, e-g).

Biochemical examination of the SC. One-dimensional SDS-PAGE of SC proteins showed that the compositions and amounts of proteins in the Arnt-null and control epidermis were virtually identical (data not shown).

We next analyzed the intercorneocyte lipids, which consist mainly of ceramides, cholesterol, and fatty acids and mediate the skin barrier function. In particular, skin-specific ceramides play a crucial role in barrier formation. The contents of cholesterol and fatty acids of Arnt-null mice did not differ from those of the WT mice, using HPTLC analysis. In addition, HPLC analysis of fatty acids derivatized with 9-anthryldiazomethane showed that fatty acid compositions (mol \% of the total free fatty acids) were virtually identical for Arnt-null mice and WT littermates in the chain-length range of 14-30: C14:0 + C18:2, 4.3 and 2.2; C16:0, 11.7 and 15.5; C18:0, 13.6 and 18.7; C18:1, 3.7 and 1.34; C20:0, 1.0 and 1.1; C22:0, 3.8 and 3.8; C24:0, 16.3 and 15.3; C25:0, 2.8 and 2.5; C26:0, 17.2 and 14.8; C28:0, 1.7 and 1.1; and C30:0, 0.6 and 0.2, respectively. We next compared SC ceramide compositions in the WT and Arnt-null mice using HPTLC and microbore normal-phase HPLC/ion-trap mass spectrometry, and hereafter we will use the epidermal ceramide (Cer) nomenclature proposed by Motta et al. (26) (Figure 5a). HPTLC showed that the amounts of the least polar ceramide, Cer(EOS), which contains the $\omega$-hydroxy acyl group $(\mathrm{O})$ esterifying with fatty acid (E), mainly linoleate, and sphingosine (4-sphingenine; $\mathrm{S}$ ), were 44\% lower in Arnt-null mice than in WT mice (1.50 $\mu \mathrm{g} / \mathrm{mg}$ tissue), and that the amounts of $\operatorname{Cer}(\mathrm{NP})$, which contains the non-hydroxy acyl group $(\mathrm{N})$ and phytosphingosine (4-hydroxysphinganine; P) were 93\% lower in Arnt-null than in WT mice $(0.16 \mu \mathrm{g} / \mathrm{mg}$ tissue) (Figure $5 b)$. In contrast, no difference in the amounts of Cer(NS), which contains $\mathrm{N}$ and $\mathrm{S}$, was observed (3.3 and $3.9 \mu \mathrm{g} / \mathrm{mg}$ tissue for WT and Arnt-null mice, respectively) (Figure $5 b)$. Cer(OS) $\omega$-hydroxyceramides also esterify with outer surface proteins of the cornified-cell envelope, presumably forming part of the skin barrier. Cer(OS) prepared with exhaustive extraction of free SC lipids followed by mild alkaline hydrolysis was resolved on HPTLC as major two bands, and bound Cer(OS) contents estimated from the intensity of these bands in the Arnt-null SC $(11.9 \pm 2.9$ $\mu \mathrm{g} / \mathrm{mg}$ tissue lyophilized) were $55 \%$ of those of the WT $(21.4 \pm 5.0 \mu \mathrm{g} / \mathrm{mg}$ tissue lyophilized). Of special note, reductions in the free $\mathrm{Cer}(\mathrm{EOS})$ and bound $\mathrm{Cer}(\mathrm{OS})$ contents in the Arnt-null SC were identical.

In contrast to HPTLC, HPLC/ESI-ion-trap mass spectrometry provides information about ceramide structures at the molecular-species levels, which were con-
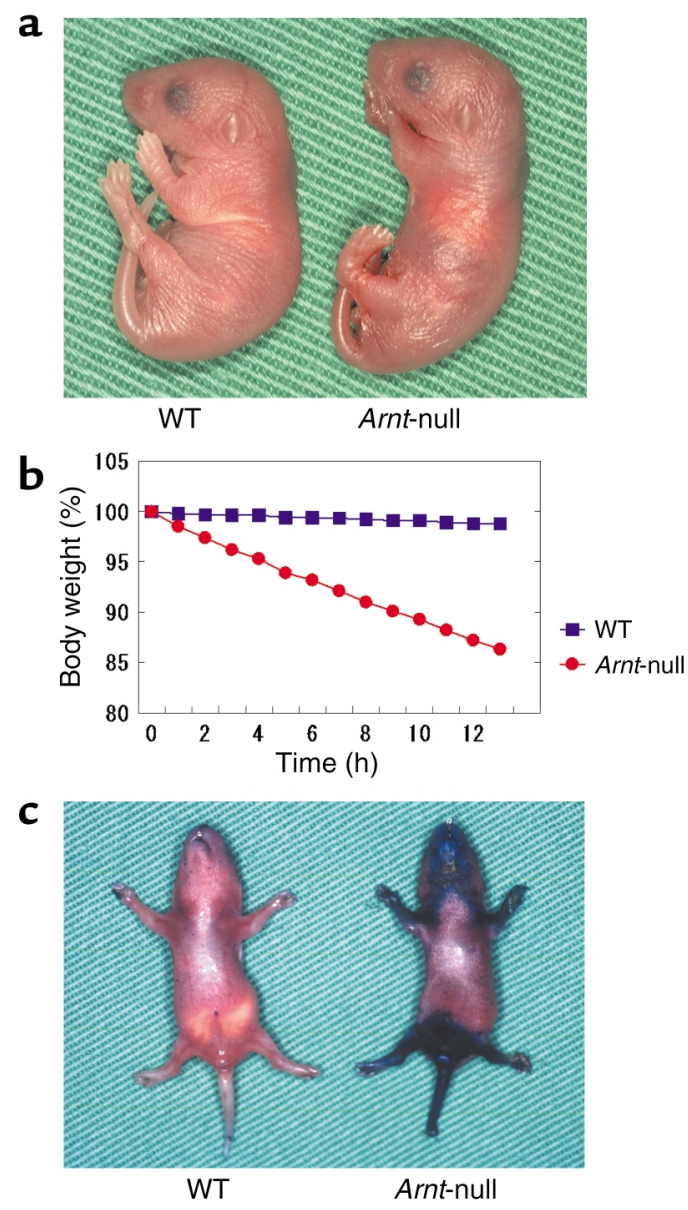

\section{Figure 2}

Fatal impairment of the epidermal barrier in Arnt-null mice. (a) Newborn mice immediately after birth. The Arnt-null mice did not show any abnormal appearance. (b) Hourly measurements of body weight. The Arnt-null mice lost weight rapidly and finally died within 24 hours. (c) Skin-permeability assay with $0.1 \%$ toluidine blue. The ventral neck and perineal regions of the Arnt-null mice were dyed blue. 
Table 2

Increased trans-epidermal water loss in Arnt-null mice

\begin{tabular}{lcc} 
& Ventral neck $(n=9)$ & Back $(n=6)$ \\
WT & $1.82 \pm 1.02$ & $1.23 \pm 0.45$ \\
Arnt-null & $9.68 \pm 3.26$ & $1.77 \pm 1.68$ \\
\hline
\end{tabular}

Values $\left(\mathrm{g} / \mathrm{h} / \mathrm{m}^{2}\right)$ are shown as means $\pm \mathrm{SD}$. Trans-epidermal water loss of the ventral neck in Arnt-null mice was significantly elevated $(P<0.01)$. The number of samples is shown $(n)$.

firmed by the $m / z$ values of ceramide molecular ions and on-line MS/MS (Figures 6-8). Alternate polarity switching on ESI allowed us to obtain simultaneously the positive- and negative-ion mass spectra of ceramides at each peak resolved on a single normal-phase chromatographic run (Figure 6), thus helping us to identify the structures (23). In the positive-ion mode, the major WT SC ceramides eluted as complex total ion current (TIC) profiles on a Lichrospher Si 100 column. Closer inspection of chromatograms of the abundant ions with a given $m / z$ value across the TIC profiles revealed four distinct elution peaks that contained the most abundant protonated molecular $[\mathrm{M}+\mathrm{H}]^{+}$ions, with $m / z$ values of $1,066,678$, 696, and 694 (Figure 7a). These values corresponded, respectively, to the $m / z$ values of ceramide molecular species: $\quad N$-linoleoyl-oxy-C34:1-Cer(EOS), $\quad N$-C26:0Cer(NS), $N$-C26:0-Cer(NP), and Cer(AS) with $\alpha$-hydroxy fatty acid (A) of C26:0 and S, which eluted in this increasing polarity order as determined by HPTLC. Negative-ion ESI gave either deprotonated $[\mathrm{M}-\mathrm{H}]^{-}$or more abundant formate adduct $[\mathrm{M}+\mathrm{HCOO}]^{-}$ions of ceramides under the conditions used, and the $m / z$ values of these negative ions were consistent with those of the corresponding positive ions (Figure 6). The ceramide structures expected from the molecular masses determined by a full-scan mass spectrometry were confirmed by on-line MS/MS. A positive-ion MS/MS spectrum of Cer(EOS) of $m / z 1,066$ showed the presence of ions of $m / z 786$ and 804 arising from the neutral loss of linoleic acid as an acid and as a ketene, respectively. The structures of Cer(NS), Cer(NP), and Cer(AS) were confirmed by fragmentation patterns around the head groups of the most intense $[\mathrm{M}-\mathrm{H}]^{-}$ ions, of $m / z 676,694$, and 692 , respectively $(27,28)$.

In both WT and Arnt-null mice, the mass spectra of SC Cer(EOS) were similar: its molecular species mainly consisted of a homologous series of saturated and mono-unsaturated long-chain $\omega$-hydroxy acyl groups (C30-C36), linoleate, and 4-sphingenine. Chromatograms of representative $[\mathrm{M}+\mathrm{H}]^{+}$ions of $m / z 1,066$ plus their dehydrated ions $(m / z 1,048)$, which are characteristic of ceramides with 4-sphingenyl moiety, showed single peaks in the range where a variety of ceramide species elute. The relative peak area normalized to Cer(NS) was used for a rough comparison of the contents of each ceramide species (Figure $7 \mathrm{~b}$ ), because the contents of Cer(NS) were similar between the two animal groups (Figure $5 \mathrm{~b}$ ). The normalized peak area of Cer(EOS) in the Arnt-null mice was significantly small- er than that in the WT. Notably, $[\mathrm{M}+\mathrm{H}]^{+}$ions of Cer(NP), identified as a $696-m / z$ peak of the major species with C26:0 in the WT, was hardly detectable in Arnt-null mice (Figure 7a). These results were consistent with those of HPTLC. Furthermore, the epidermis-specific Arnt deficiency caused significant ceramide structural alterations in Cer(NS): the $m / z$ value of the most intense ions of Cer(NS) was 2 mass units larger in Arntnull mice than that in the WT mice (Figure 8), and the abundance of dehydrated ions that is characteristic of ceramides that contain 4-sphingenine decreased greatly. MS/MS analysis of ions of both $m / z 678$ and $m / z 680$ clearly showed that the sphingoid base fragments $(\mathrm{m} / z$ 266,284 , and 302 ), arising from cleavage at the 2 -amide linkage of ions of $m / z 680$, were 2 mass units larger than the fragments of $678-m / z$ ions. This demonstrates that the sphingosine base had been replaced by sphinganine in Arnt-null mice (Figure 8). The same results were obtained for Cer(AS), but unlike Cer(NS) contents, Cer(AS) contents were lower in Arnt-null than in WT mice. These results suggest that ARNT regulates dihy-
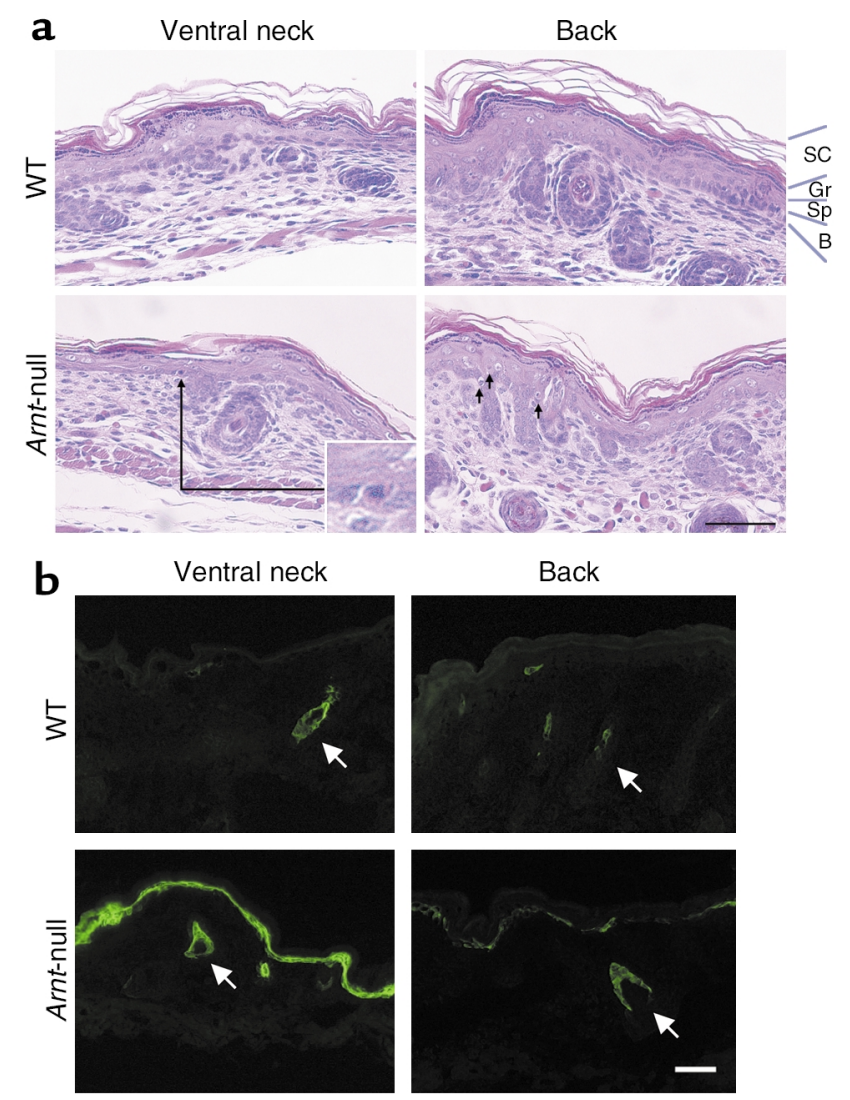

\section{Figure 3}

Histopathological analysis of the epidermis from Arnt-null mice and WT littermates. (a) H\&E staining of the epidermis in the ventral neck and back regions. SC from Arnt-null mice is tightly packed, especially in the ventral neck region. Sunburn cells, indicated by arrows, are observed in the basal layer in Arnt-null mice. The long arrow indicates a magnified sunburn cell in the inset. Gr, granular layer; Sp, spinous layer; B, basal layer. Bar: $20 \mu \mathrm{m}$. (b) The expression of keratin 6 is strongly induced in basal cells, especially in the ventral neck region. Arrows indicate the expression of keratin 6 in hair follicles. Bar: $50 \mu \mathrm{m}$. 
a

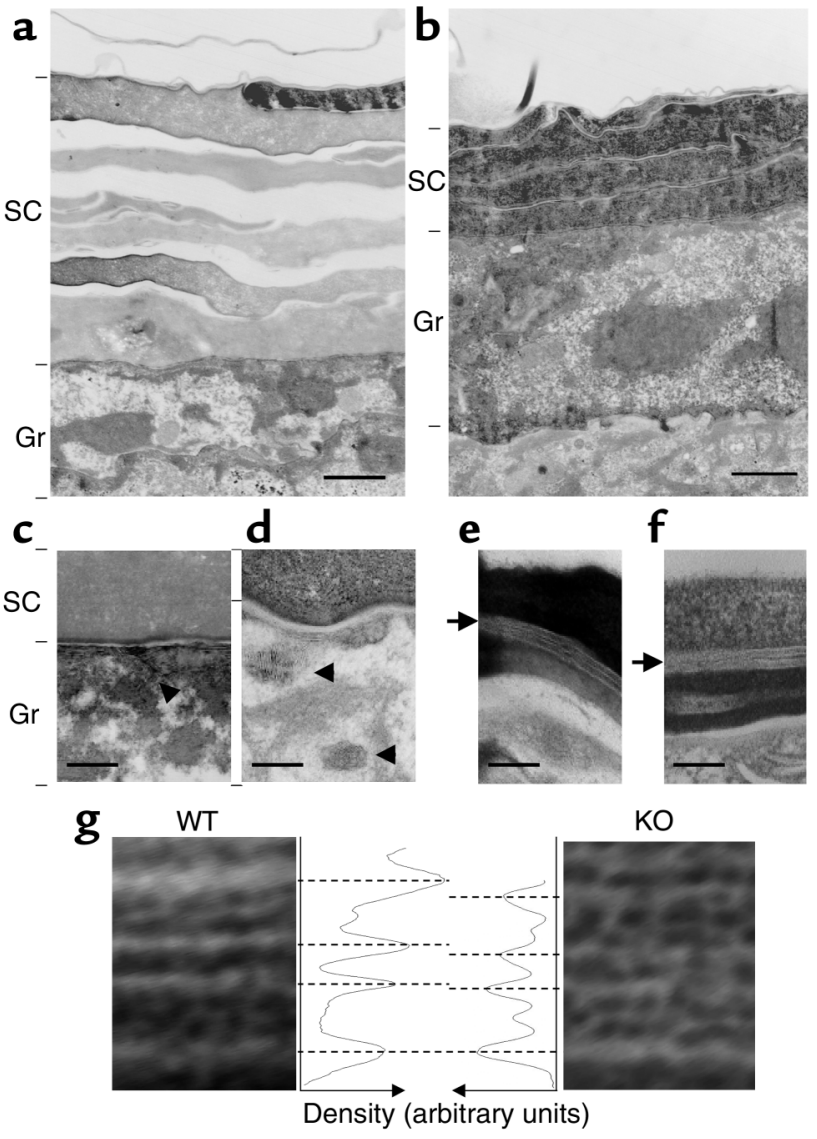

droceramide desaturase activity in epidermis, because the desaturases can catalyze the formation of both 4-sphingenyl and 4-hydroxysphinganyl moieties (29).

Two known desaturase isoenzymes exist: DES-1 and DES-2. DES-1 prefers 4-desaturation, and DES-2 prefers 4-hydroxylation (29). The transcript levels of both isoenzymes were examined by quantitative PCR. We found considerable reduction of Des-2 but not Des-1 mRNA in Arnt-null keratinocytes (Figure 9). However, desaturase activity in mouse epidermis was too low (less than one-thirtieth of that reported in rat epidermis) to obtain reproducible results.

\section{Discussion}

For this study, we generated keratinocyte-specific Arntdeficient mice with the Cre-loxP system. Although conventional Arnt-deficient mice are lethal at embryonic day 10.5 (E10.5) because of impaired angiogenesis and placental dysfunction (6, 7), keratinocyte-specific Arntdeficient mice are born within the expected mendelian frequency, thus making it possible to study the functions of ARNT in skin. However, these mice died with-

\section{Figure 5}

Profiles of SC ceramides of WT and Arnt-null mice. (a) Structures of the major murine SC ceramides. The nomenclature of Motta et al. (26) is used. (b) HPTLC of SC ceramides of WT and Arnt-null mice, performed as described in Methods. The most polar ceramide, Cer(AP), was not detectable in this HPTLC plate.

\section{Figure 4}

EM analysis. EM images of SC from WT (a, c, and $\mathbf{e})$ and Arnt-null mice ( $\mathbf{b}, \mathbf{d}$, and $\mathbf{f}$ ). SC from Arnt-null mice is tightly packed, and abnormal vesicles are present (compare $\mathbf{a}$ and $\mathbf{b}$ ). In the granularlayer keratinocytes, lamellar bodies with disk-like contents were observed and excreted normally into the intercellular space of the SC (c and $\mathbf{d}$ ). Arrowheads indicate lamellar bodies. The intercellular lamellar structure appeared normal (e and $\mathbf{f})$. Arrows indicate the intercellular lamellar structure. Bars: $1 \mu \mathrm{m}$ (a and b), $0.2 \mu \mathrm{m}$ (c and $\mathbf{d}$ ), and $0.1 \mu \mathrm{m}$ (e and $\mathbf{f}$ ). (g) A closer comparison of SC lamellae in WT and Arnt-null mice. Their images were obtained by scanning of negatives taken at a primary magnification of $\times 40,000$ at 12 -bit grayscale resolution and were analyzed with $\mathrm{NIH}$ ImageJ software (48).

in 24 hours after birth, probably from severe dehydration resulting from skin barrier dysfunction. This is indeed demonstrated by an increased rate of trans-epidermal water loss and an increased permeability of toluidine blue across the skin all over the body surface, but with regionally varying severity that was greatest in the ventral neck and perineal regions. The phenotype could be rescued to some degree by application of salve to the skin. This suggests that the important functions of ARNT in barrier formation vary from region to region in skin. Hardman et al. reported that the skin barrier in normal mice is formed in a patterned manner, spreading over embryos from specific start sites around E16 to the final ventral neck region on E17 late in gestation (17). Toluidine blue staining patterns in control mice on E16 were very similar to those in Arnt-null mice during birth, indicating that ARNT participates temporarily in the development of the skin barrier.

To characterize SC ceramides at the molecular-species levels, we used a normal-phase HPLC/ESI-ion-trap mass spectrometry system. This can separate complex mixtures of SC ceramides, acquire data-dependent MS/MS spectra
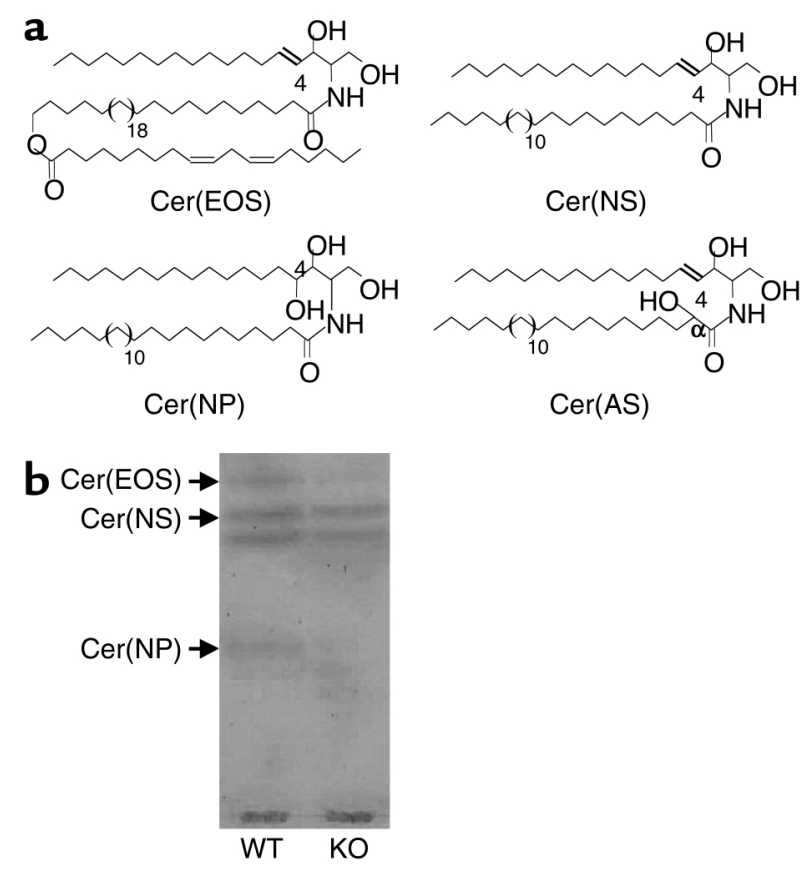
over the entire chromatogram range, and acquire positive- and negative-ion spectra by alternate polarity switching, thereby facilitating identification of the structures of SC ceramides (23). The positive-ion full-scan spectra of the major murine SC ceramides obtained in this study were very similar to those obtained previously by matrixassisted laser desorption ionization mass spectrometry of samples separated by HPTLC and then extracted (30), except that sodiated molecular ions (larger by 22 mass units than the corresponding protonated ions) were predominant in the latter. In that study, the ceramide structures were not confirmed by mass spectrometry, but their presence was assumed on the basis of the molecular mass of the sphingoid base and a comparison of HPTLC behaviors of ceramides. In contrast, we could unequivocally identify ceramide structures by means of on-line MS/MS in either positive- or negative-ion mode.

The combined use of HPTLC and mass spectrometry analyses demonstrated that keratinocyte-specific Arnt disruption resulted in significant changes in the amount and composition of ceramides, one of the major SC lipids, but not the others, such as cholesterol and fatty acids. The most prominent changes in the ceramide compositions of the Arnt-null epidermis were observed in $\operatorname{Cer}(\mathrm{NS})$ and $\operatorname{Cer}(\mathrm{AS})$. The 4-sphingenine that these ceramides normally contain was largely replaced by sphinganine. The proportion of dihydroceramide species lacking a double bond at position 4 is increased. Ceramides are first synthesized as $\mathrm{N}$-acyl-sphinganine, or dihydroceramide, via the sphingoid base synthetic pathway starting from serine and palmitoyl- or stearoylCoA. Desaturation at position 4 of the sphinganyl moiety then yields Cer(NS) (31). The increase in the proportion of the dihydro species of Cer(NS) in the Arnt-null epidermis therefore suggests that $\Delta 4$-desaturase activity is downregulated in the Arnt-null epidermis.

A recent bioinformatics study detected the presence of two sphingolipid $\Delta 4$-desaturase, or dihydroceramide desaturase, cDNAs, Des-1 and Des-2, in murine expressed sequence tags (ESTs) (29). In cultured keratinocytes from Arnt-null epidermis, Des-2 but not Des-1 transcript levels were indeed decreased significantly. Since there are consensus AHR/ARNT (TNGCGTG) and HIF1 $\alpha /$ ARNT (TACGTG) responsive elements at $-2,492$ and $-2,359$, respectively, of the Des-2 gene, we believe that ARNT directly regulates production of the Des-2 transcript. 4-Desaturation and 4-hydroxylation are known to be mechanistically similar (32), and it was demonstrated in a yeast expression system that DES- 1 and DES- 2 exhibited both activities; human DES-1 greatly preferred 4-desaturation (a desaturation/hydroxylation ratio of 60:70), and mouse DES-2 was bifunctional (a ratio of 2.5) (29). In light of its substrate specificity, DES-2 deficiency can account for the considerable decrease in Cer(NP) levels as well as the increased dihydro-Cer(NS) proportions in the Arnt-null epidermis. The differential contributions of DES- 1 and DES- 2 to ceramide desaturation, however, remain to be clarified.

We next used mass spectrometry to determine $\Delta 4$-desaturase activities in murine epidermis in order to
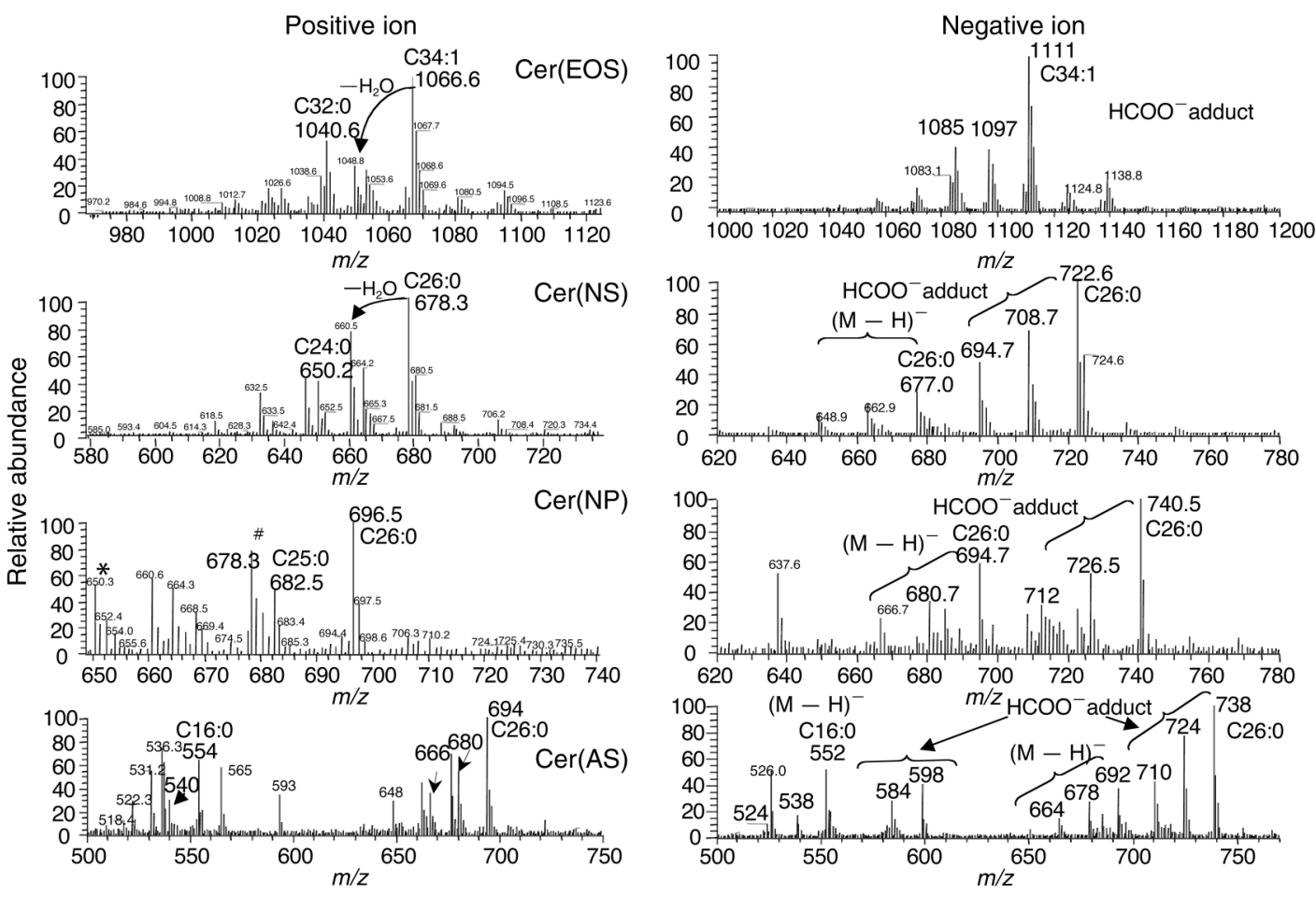

Figure 6

HPLC/ion-trap mass spectroscopy of SC ceramides. Positive- and negative-ion spectra of WT SC ceramides, acquired by an alternate polarity switching method. * Major peak for Cer(NS) containing C24:0 ( $\mathrm{m} / \mathrm{z}$ 650); ${ }^{*}$ major peak for Cer(NS) containing C26:0 ( $\mathrm{m} / \mathrm{z}$ 678). 

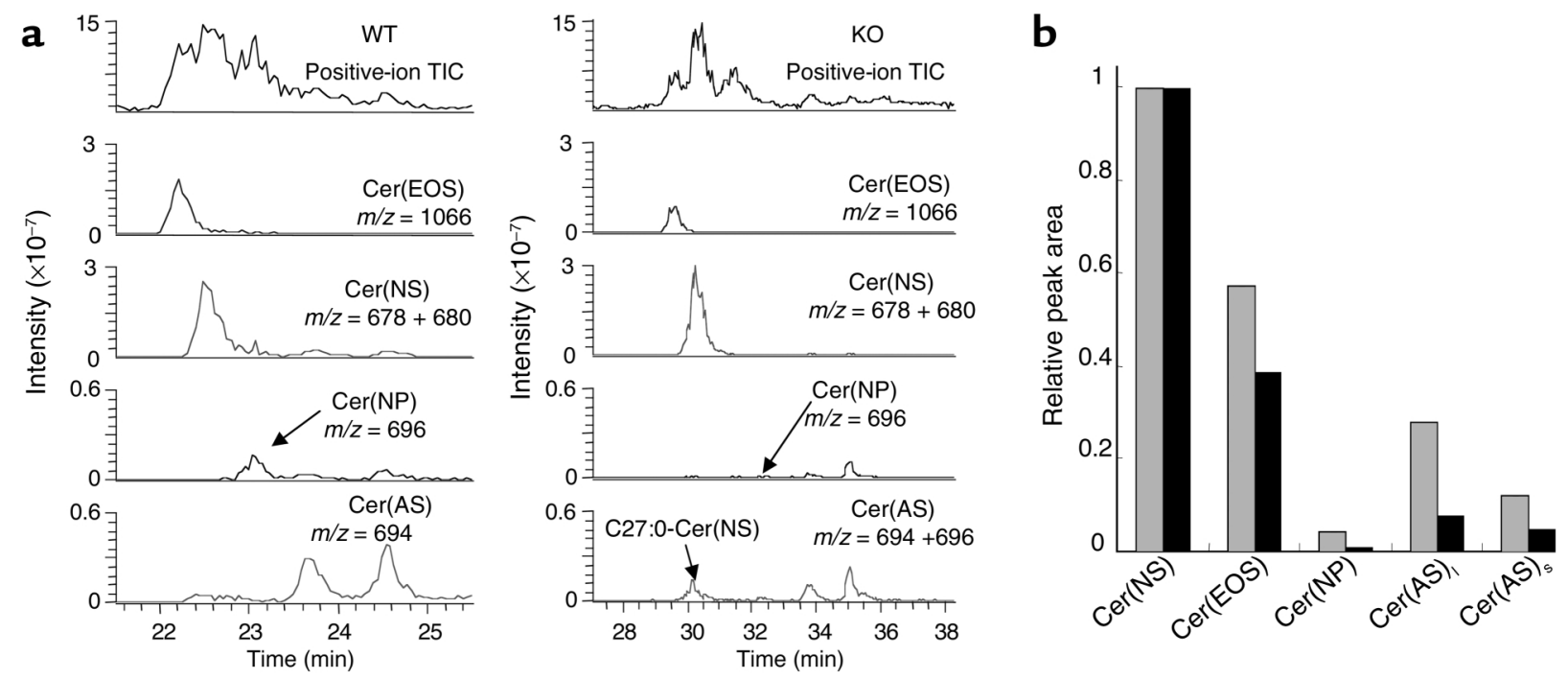

\section{Figure 7}

HPLC/ion-trap mass spectroscopy of SC ceramides in WT and Arnt-null mice. (a) Total ion current (TIC) and ion chromatograms of the most intense signals of $\operatorname{Cer}(\mathrm{EOS}), \operatorname{Cer}(\mathrm{NS}), \operatorname{Cer}(\mathrm{NP})$, and $\operatorname{Cer}(\mathrm{AS})$ in the positive-ion mode. Where the $m / z$ values of these signals were different from each other in WT and Arnt-null mice, the sum of ion chromatograms of both $m / z$ values, except WT Cer(AS), is presented. Ion chromatograms of ceramides containing 4-sphingenine are presented as the sum of the most intense $[\mathrm{M}+\mathrm{H}]^{+}$ions and their dehydrated ions. (b) Ratios of peak areas of Cer(EOS), Cer(NP), and Cer(AS) to those of Cer(NS) in WT (gray bars) and Arnt-null (black bars) SC. To generate a reconstituted chromatogram for each ceramide species, ceramide-related signals with intensities of greater than $5 \%$ of that of the most intense peak were used. Cer(AS) was divided into Cer(AS)s, with shorter-chain acyl moieties (mainly C16:0 and C18:0), and Cer(AS), with longer-chain acyl moieties (mainly C24:0-C26:0).

clearly identify reaction products. We modified the conditions used in a radiometric assay for desaturase activity in fetal rat skin (33) to look for optimal assay conditions including: substrate specificity for the chain length of dihydroceramides, C16:0 or a more natural $\mathrm{C} 24: 0 ; \mathrm{pH}$ dependence of activity in the range of 5.5-8.5; the effects of detergents, $\alpha$ - and $\beta-\mathrm{NADH}$, and FAD on activity; and isolation and preparation methods of enzyme sources. FAD is a coenzyme in the microsomal electron transport system containing the desaturases. However, we could only detect very low levels of dihydroceramide desaturase activity (near background noise level) in murine epidermis. This precluded direct comparison of activities in Arnt-null and WT mouse epidermis. The reason for the low level of activity is unclear, but species differences are a possible explanation.

The importance of bulk ceramides in the epidermal barrier function has been established, but the roles of specific ceramide species have not yet been clarified. It is generally accepted that ceramides containing $\omega$-hydroxy fatty acid - that is, $\mathrm{Cer}(\mathrm{OS})$ bound to the protein envelope and Cer(EOS) in lipid lamellae - are essential for maintaining the SC lamellar structures (34), and thus the barrier function (35). The reduction in levels of both of these $\omega$-hydroxyceramides in Arnt-null mice was consistent with an impaired barrier function. The most characteristic change in the contents of the SC ceramide species in Arnt-null mice was a marked decrease in Cer(NP). There is no close relationship between Cer(NP) contents and the quality of the barrier function, but the addition of Cer(NP) to SDS-disordered lipid lamellae reportedly restored the periodicity of lamellar structures (36). The relationship between increased dihydroceramide levels and barrier dysfunction is also unclear. In contrast to what was observed in ceramides, the lack of the trans-double bond at position 4 in dihydroceramides causes a conformational distortion that might reduce hydrogen-bonding interaction with water molecules around their head groups (37). This could result in a reduction in the tightness of the packing of lipids in SC lamellar structures and affects skin permeability.

Despite the major changes in the amount and composition of SC ceramides and the severity of functional damage to the skin barrier, the fine architecture of intercellular lipid lamellae and of their precursor lamellar bodies in the granular layer was surprisingly preserved in Arnt-null mice as observed by EM, although the spacing of SC lamellae was somewhat closer. On disruption of the Pig-a gene that encodes an enzyme involved in the first step of the GPI-anchor biosynthesis (16) and the $\beta$-glucocerebrosidase gene (38), SC lamellae and lamellar body structures were severely damaged, but the extent of water loss from the skin surface was not as significant as in the Arnt-null mice. This suggests that not only lamellar structures but also tight packing of SC lipids at the molecular levels are needed to prevent trans-epidermal water loss. To further clarify the structure-function relationship of the epidermal barrier, more intensive studies on lamellar structures at the molecular or atomic levels, using physicochemical methods, will be required (39). In this context, the epidermal barrier function was found to be impaired in the skin of atopic dermatitis and psoriasis. HPTLC 


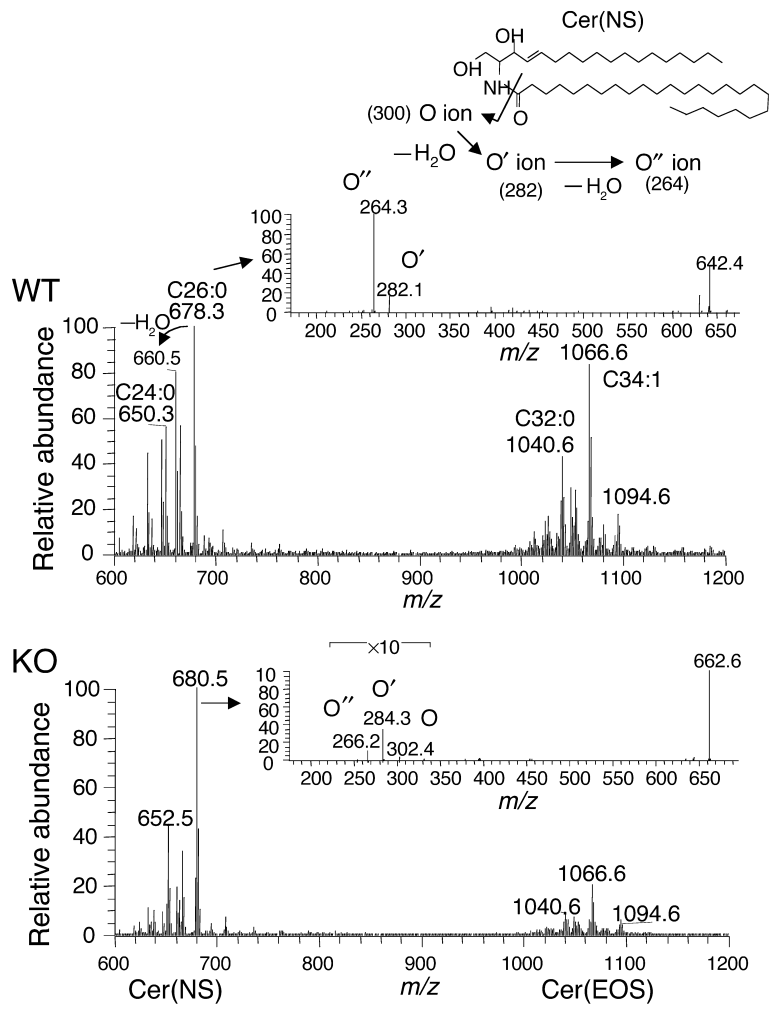

analysis indicated that $\mathrm{Cer}(\mathrm{EOS})$ and $\mathrm{Cer}(\mathrm{NP})$ levels were significantly diminished in these skin diseases (40). It would be of interest to compare the detailed structures of lamellae of these patients and of Arnt-null mice.

Arnt-null epidermis showed generally preserved morphology, but remarkable pathology, including an increase in the number of apoptotic cells. There are at least three sphingolipid-dependent mechanisms that elicit apoptosis in cultured human keratinocytes: accumulation of excess ceramide, accumulation of excess sphinganine, and depletion of ceramide or complex sphingolipids (41). However, it is difficult to determine whether apoptosis observed in the Arnt-deficient epidermis was due to altered compositions of ceramide. Although apoptotic keratinocytes were detected in the epidermis of Arnt-null mice, we did not detect any epidermal hypoplasia. Other signaling pathways may compensate for the deficiency of Arnt, as observed in Bcl- $x L$-deficient mice that show accelerated keratinocyte apoptosis but normal architecture in the epidermis (42). Keratin 6 was strongly induced in the epidermis of Arnt-null mice. Expression of keratin 6 in the interfollicular epidermis, found in Arnt-null mice after birth, was indicative of either a hyperproliferative or an

\section{Figure 9}

Reduction of Des-2 expression in Arnt-null keratinocytes. Keratinocytes of newborn mice were cultured in the presence or absence of calcium, and the expression levels of Des-1 and Des-2 transcript were quantified by real-time PCR using $\beta$-actin transcript as a standard for normalization. The experiment was performed twice using keratinocytes isolated from different mice. KO, Arntnull mice; Exp, experiment.

\section{Figure 8}

Positive-ion full-scan mass and MS/MS spectra of Cer(EOS) and Cer(NS) in WT and Arnt-null mice. For comparison of the intensities, spectra of Cer(EOS) and Cer(NS) are presented together on the same trace. The upper inset shows the fragmentation patterns of Cer(NS) at the amide linkage. The $\mathrm{O}$ series ions contain the sphingoid base scaffold and undergo dehydration, generating the $\mathrm{O}^{\prime}$ and $\mathrm{O}^{\prime \prime}$ ions. The inset spectra are MS/MS spectra of $\left[\mathrm{M}-\mathrm{H}_{2} \mathrm{O}+\mathrm{H}\right]^{+}$ions $(\mathrm{m} / z$ $660)$ of Cer(NS) in WT SC (upper panel) and of $[\mathrm{M}+\mathrm{H}]^{+}$ions $(\mathrm{m} / z$ 680) of Cer(NS) in Arnt-null SC (lower panel).

activated state of the keratinocytes. It might reflect a break in the skin barrier function, since keratin 6 is induced in the epidermis as early as 12 hours after barrier disruption (43)

It is known that ARNT heterodimerizes with other bHLH-PAS proteins such as AHR and HIF $1 \alpha$ to form a transcriptionally active DNA-binding complex $(2,44)$. The AHR/ARNT heterodimer, with exogenous ligands such as dioxin, binds an atypical E-box DNA sequence, TNGCGTG, and activates a number of target genes. However, conventional $\mathrm{Abr}^{-1-}$ mice did not show any overt phenotype in skin (45), indicating that the AHR/ARNT heterodimer cannot be responsible for the phenotype observed in this study. The HIF1 $\alpha /$ ARNT heterodimer senses oxygen concentration and activates a number of hypoxia/hypoglycemia-regulated genes. To explore the functions of this heterodimer, the conditional allele for Hifl $\alpha$ has been made. Keratinocyte-specific (K5-Cre) disruption of Hifl $\alpha$ led to no overt phenotype (S. Tomita et al., unpublished observations), suggesting that the HIF $1 \alpha /$ ARNT heterodimer is not responsible for the phenotype observed in this study. Although SIM1 and SIM2 are other candidates that can form heterodimers with ARNT (46) and can possibly activate the desaturase gene in the epidermis (47), they
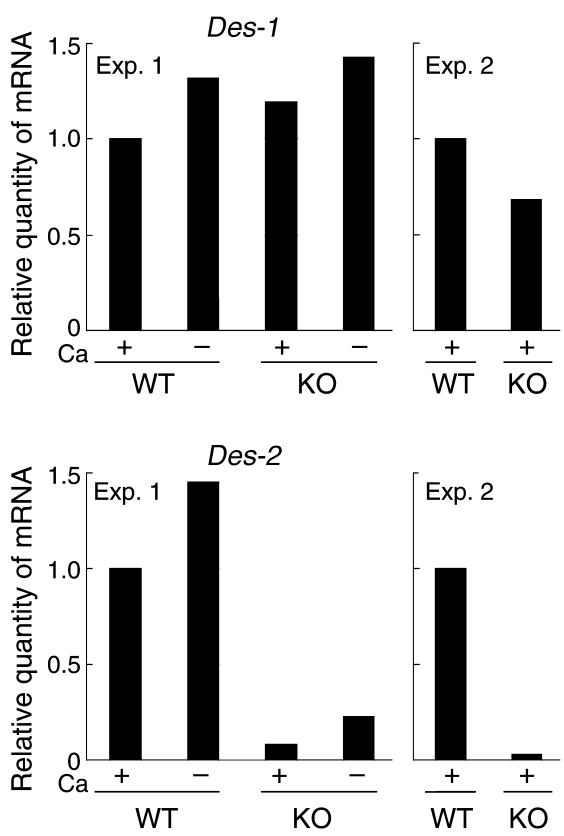
are not expressed in the epidermis. On the basis of these findings, we propose that a novel bHLH-PAS protein, which can heterodimerize with ARNT, exists in the epidermis. This novel heterodimer, which may work as a sensor for environmental stimuli, would be involved in the activation of dihydroceramide desaturase. Alternatively, it is possible that the ARNT/ARNT homodimer performs the same function as the novel complex.

In conclusion, keratinocyte-specific deficiency of Arnt demonstrated that ARNT regulates essential roles for the ceramide biosynthetic pathway, such as the desaturase step, and that the altered composition of ceramides in the epidermis results in severe damage to the barrier function.

\section{Acknowledgments}

This work was supported by Senri Life Science Foundation and a Grant-in-Aid for Scientific Research from the Ministry of Education, Culture, Sports, Science and Technology of Japan. We thank Vincent W. Keng for critical reading of the manuscript.

1. Gu, Y.Z., Hogenesch, J.B., and Bradfield, C.A. 2000. The PAS superfamily: sensors of environmental and developmental signals. Annu. Rev. Pharmacol. Toxicol. 40:519-561.

2. Huang, L.E., Gu, J., Schau, M., and Bunn, H.F. 1998. Regulation of hypoxia-inducible factor 1alpha is mediated by an O2-dependent degradation domain via the ubiquitin-proteasome pathway. Proc. Natl. Acad. Sci. U. S. A. 95:7987-7992.

3. Sogawa, K., et al. 1995. Possible function of Ah receptor nuclear translocator (Arnt) homodimer in transcriptional regulation. Proc. Natl. Acad. Sci.U.S. A. 92:1936-1940.

4. Aitola, M.H., and Pelto-Huikko, M.T. 2003. Expression of Arnt and Arnt2 mRNA in developing murine tissues. J. Histochem. Cytochem. 51:41-54.

5. Jain, S., Maltepe, E., Lu, M.M., Simon, C., and Bradfield, C.A. 1998. Expression of ARNT, ARNT2, HIF1 alpha, HIF2 alpha and Ah receptor mRNAs in the developing mouse. Mech. Dev. 73:117-123.

6. Kozak, K.R., Abbott, B., and Hankinson, O. 1997. ARNT-deficient mice and placental differentiation. Dev. Biol. 191:297-305

7. Maltepe, E., Schmidt, J.V., Baunoch, D., Bradfield, C.A., and Simon, M.C. 1997. Abnormal angiogenesis and responses to glucose and oxygen deprivation in mice lacking the protein ARNT. Nature. 386:403-407.

8. Nemes, Z., Marekov, L.N., Fesus, L., and Steinert, P.M. 1999. A novel function for transglutaminase 1: attachment of long-chain omegahydroxyceramides to involucrin by ester bond formation. Proc. Natl. Acad. Sci.U.S. A. 96:8402-8407.

9. Steinert, P.M. 1996. Intermediate filaments in health and disease. Exp. Mol. Med. 28:55-63.

10. Matsuki, M., et al. 1998. Defective stratum corneum and early neonatal death in mice lacking the gene for transglutaminase 1 (keratinocyte transglutaminase). Proc. Natl. Acad. Sci. U. S. A. 95:1044-1049.

11. Elias, P.M., and Menon, G.K. 1991. Structural and lipid biochemical correlates of the epidermal permeability barrier. Adv. Lipid Res. 24:1-26.

12. Wertz, P.W., and Downing, D.T. 1983. Ceramides of pig epidermis: structure determination. J. Lipid Res. 24:759-765.

13. Wertz, P.W., Miethke, M.C., Long, S.A., Strauss, J.S., and Downing, D.T. 1985. The composition of the ceramides from human stratum corneum and from comedones. J. Invest. Dermatol. 84:410-412.

14. Tomita, S., Sinal, C.J., Yim, S.H., and Gonzalez, F.J. 2000. Conditional disruption of the aryl hydrocarbon receptor nuclear translocator (Arnt) gene leads to loss of target gene induction by the aryl hydrocarbon receptor and hypoxia-inducible factor 1alpha. Mol. Endocrinol. 14:1674-1681.

15. Lakso, M., et al. 1996. Efficient in vivo manipulation of mouse genomic sequences at the zygote stage. Proc. Natl. Acad. Sci. U. S. A. 93:5860-5865.

16. Tarutani, M., et al. 1997. Tissue-specific knockout of the mouse Pig-a gene reveals important roles for GPI-anchored proteins in skin development. Proc. Natl. Acad. Sci. U. S. A. 94:7400-7405.

17. Hardman, M.J., Sisi, P., Banbury, D.N., and Byrne, C. 1998. Patterned acquisition of skin barrier function during development. Development. 125:1541-1552.

18. Hou, S.Y., et al. 1991. Membrane structures in normal and essential fatty acid-deficient stratum corneum: characterization by ruthenium tetroxide staining and x-ray diffraction. J. Invest. Dermatol. 96:215-223.
19. Bligh, E.G., and Dyer., W.J. 1959. A rapid method of total lipid extraction and purification. Can. J. Biochem. Physiol. 37:911-917.

20. Hara, M., Uchida, Y., Haratake, A., Mimura, K., and Hamanaka, S. 1998. Galactocerebroside and not glucocerebroside or ceramide stimulate epidermal beta-glucocerebrosidase activity. J. Dermatol. Sci. 16:111-119.

21. Radin, N.S. 1981. Extraction of tissue lipids with a solvent of low toxicity. Methods Enzymol. 72:5-7.

22. Uchida, Y., et al. 2000. Epidermal sphingomyelins are precursors for selected stratum corneum ceramides. J. Lipid Res. 41:2071-2082.

23. Ito, M., Tchoua, U., Okamoto, M., and Tojo, H. 2002. Purification and properties of a phospholipase A2/lipase preferring phosphatidic acid, bis(monoacylglycerol) phosphate, and monoacylglycerol from rat testis. J. Biol. Chem. 277:43674-43681.

24. Sano, S., et al. 1999. Keratinocyte-specific ablation of Stat3 exhibits impaired skin remodeling, but does not affect skin morphogenesis. EMBO J. 18:4657-4668

25. Young, A.R. 1987. The sunburn cell. Photodermatol. 4:127-134.

26. Motta, S., et al. 1993. Ceramide composition of the psoriatic scale. Biochim. Biophys. Acta. 1182:147-151.

27. Hsu, F.F., and Turk, J. 2002. Characterization of ceramides by low energy collisional-activated dissociation tandem mass spectrometry with negative-ion electrospray ionization. J. Am. Soc. Mass Spectrom. 13:558-570.

28. Raith, K., and Neubert, R. 1998. Structural studies on ceramides by electrospray tandem mass spectrometry. Rapid Commun. Mass Spectrom. 12:935-938.

29. Ternes, P., Franke, S., Zahringer, U., Sperling, P., and Heinz, E. 2002. Identification and characterization of a sphingolipid delta 4-desaturase family. J. Biol. Chem. 277:25512-25518.

30. Doering, T., et al. 1999. Sphingolipid activator proteins are required for epidermal permeability barrier formation. J. Biol. Chem. 274:11038-11045.

31. Merrill, A.H., Jr. 2002. De novo sphingolipid biosynthesis: a necessary, but dangerous, pathway. J. Biol. Chem. 277:25843-25846.

32. Shanklin, J., and Cahoon, E. 1998. Desaturation and related modifications of fatty acids. Annual Review of Plant Physiology and Plant Molecular Biology. 49:611-641

33. Mikami, T., Kashiwagi, M., Tsuchihashi, K., Akino, T., and Gasa, S. 1998. Substrate specificity and some other enzymatic properties of dihydroceramide desaturase (ceramide synthase) in fetal rat skin. J. Biochem. (Tokyo). 123:906-911.

34. Bouwstra, J.A., et al. 1998. Role of ceramide 1 in the molecular organization of the stratum corneum lipids. J. Lipid Res. 39:186-196.

35. Behne, M., et al. 2000. Omega-hydroxyceramides are required for corneocyte lipid envelope (CLE) formation and normal epidermal permeability barrier function. J. Invest. Dermatol. 114:185-192.

36. Hatta, I., Ohta, N., Ban, S., Tanaka, H., and Nakata, S. 2001. X-ray diffraction study on ordered, disordered and reconstituted intercellular lipid lamellar structure in stratum corneum. Biophys. Chem. 89:239-242.

37. Li, L., Tang, X., Taylor, K.G., DuPre, D.B., and Yappert, M.C. 2002. Conformational characterization of ceramides by nuclear magnetic resonance spectroscopy. Biophys. J. 82:2067-2080.

38. Holleran, W.M., et al. 1994. Consequences of beta-glucocerebrosidase deficiency in epidermis. Ultrastructure and permeability barrier alterations in Gaucher disease. J. Clin. Invest. 93:1756-1764.

39. Bouwstra, J.A., Honeywell-Nguyen, P.L., Gooris, G.S., and Ponec, M. 2003. Structure of the skin barrier and its modulation by vesicular formulations. Prog. Lipid Res. 42:1-36.

40. Bleck, O., et al. 1999. Two ceramide subfractions detectable in Cer(AS) position by HPTLC in skin surface lipids of non-lesional skin of atopic eczema. J. Invest. Dermatol. 113:894-900.

41. Tolleson, W.H., et al. 1999. Fumonisin B1 induces apoptosis in cultured human keratinocytes through sphinganine accumulation and ceramide depletion. Int. J. Oncol. 14:833-843.

42. Umeda, J., et al. 2003. In vivo cooperation between Bcl-xL and the phosphoinositide 3-kinase-Akt signaling pathway for the protection of epidermal keratinocytes from apoptosis. FASEB J. 17:610-620.

43. Ekanayake-Mudiyanselage, S., et al. 1998. Expression of epidermal keratins and the cornified envelope protein involucrin is influenced by permeability barrier disruption. J. Invest. Dermatol. 111:517-523.

44. Reyes, H., Reisz-Porszasz, S., and Hankinson, O. 1992. Identification of the Ah receptor nuclear translocator protein (Arnt) as a component of the DNA binding form of the Ah receptor. Science. 256:1193-1195.

45. Gonzalez, F.J., and Fernandez-Salguero, P. 1998. The aryl hydrocarbon receptor: studies using the AHR-null mice. Drug Metab. Dispos. 26:1194-1198.

46. Probst, M.R., Fan, C.M., Tessier-Lavigne, M., and Hankinson, O. 1997. Two murine homologs of the Drosophila single-minded protein that interact with the mouse aryl hydrocarbon receptor nuclear translocator protein. J. Biol. Chem. 272:4451-4457.

47. Ema, M., et al. 1996. Two new members of the murine Sim gene family are transcriptional repressors and show different expression patterns during mouse embryogenesis. Mol. Cell. Biol. 16:5865-5875.

48. ImageJ downloads. http://rsbweb.nih.gov/ij/download.html. 